\title{
Property enhancement of optically transparent bionanofiber composites by acetylation
}

\section{AUTHOR(S):}

Nogi, Masaya; Abe, Kentaro; Handa, Keishin; Nakatsubo, Fumiaki

\section{CITATION:}

Nogi, Masaya ...[et al]. Property enhancement of optically transparent bionanofiber composites by acetylation. Applied Physics Letters 2006, 89(23): 233123.

\section{ISSUE DATE:}

2006-12

URL:

http://hdl.handle.net/2433/84904

\section{RIGHT:}

c 2006 American Institute of Physics. 


\title{
Property enhancement of optically transparent bionanofiber composites by acetylation
}

\author{
Masaya Nogi ${ }^{\text {a) }}$ and Kentaro Abe \\ International Innovation Center, Kyoto University, Nishikyo-ku, Kyoto 606-8501, Japan \\ Keishin Handa \\ Mitsubishi Chemical Group Science and Technology Research Center, Mitsubishi Chemical Corporation, \\ Yokohama, Kanagawa 227-8502, Japan \\ Fumiaki Nakatsubo \\ Division of Forest and Biomaterials Science, Graduate School of Agriculture, Kyoto University, Sakyo-ku, \\ Kyoto 606-8502, Japan \\ Shinsuke Ifuku and Hiroyuki Yano \\ Research Institute for Sustainable Humanosphere, Kyoto University, Uji, Kyoto 611-0011, Japan
}

(Received 14 September 2006; accepted 26 October 2006; published online 8 December 2006)

\begin{abstract}
The authors studied acetylation of bacterial cellulose (BC) nanofibers to widen the applications of $\mathrm{BC}$ nanocomposites in optoelectronic devices. The slight acetylation of $\mathrm{BC}$ nanofibers significantly reduces the hygroscopicity of $\mathrm{BC}$ nanocomposites, while maintaining their high optical transparency and thermal stability. Furthermore, the degradation in optical transparency at elevated temperature $\left(200^{\circ} \mathrm{C}\right)$ was significantly reduced by acetylation treatment. Therefore, the acetylation of bionanofibers has an extraordinary potential as treatment for property enhancement of bionanofiber composites. () 2006 American Institute of Physics. [DOI: 10.1063/1.2403901]
\end{abstract}

Bacterial cellulose (BC), cellulose produced by bacteria, consists of weblike networks of ribbon-shaped nanofibers of $10 \times 50 \mathrm{~nm}^{2}$ in cross section. ${ }^{1-3}$ Since the cross-section size is at the nanoscale, $\mathrm{BC}$ could reinforce transparent plastics with less than $10 \%$ loss of light transmittance, even at fiber contents as high as $70 \mathrm{wt} \% .{ }^{4}$ Furthermore, the high transparency was demonstrated for several different resins with widely different refractive indices. ${ }^{5}$ The transparency was also insensitive to temperature changes, which is very important in optoelectronics applications. ${ }^{5}$

The nanofibers consist of bundles of semicrystalline extended cellulose chains, and therefore Young's modulus and tensile strength are as high as those of aramid fibers. ${ }^{6-8}$ Surprisingly, the coefficient of thermal expansion (CTE) in the axial direction is very low, as low as that of quartz. ${ }^{9}$ Hence, this $\mathrm{BC}$ nanocomposite showed very low thermal expansion, similar to that of glass. Mechanical strength was five times higher than that of engineering plastics, while maintaining the ductility. ${ }^{4}$ Furthermore, drastic reduction in thermal expansion was also observed at low $\mathrm{BC}$ contents, due to the nanofiber network. ${ }^{10}$ Thus, the concept of BC-reinforced polymer composites are expected to lead the way to a wider use of many different optically transparent polymers, in applications where high transparency as well as low thermal expansion are important.

However, when we look at future applications of $\mathrm{BC}$ nanocomposites in optoelectronic devices, the hygroscopicity of cellulose causing dimensional instability of the composites seems to be a big drawback. In this context, we studied acetylation of BC, where the hydroxyl groups of cellulose are replaced by less hydrophilic acetyl groups. ${ }^{11,12}$ The acetylation significantly reduced the hygroscopicity of

${ }^{a)}$ Electronic mail: nogi@ rish.kyoto-u.oc.jp
$\mathrm{BC}$ nanocomposites, while maintaining optical transparency and thermal stability.

$\mathrm{BC}$ pellicles with a thickness of $10 \mathrm{~mm}$ consisting of $1 \mathrm{vol} \%$ BC nanofibers and 99 vol \% water were used as the starting material. ${ }^{5}$ The pellicles were pressed at $2 \mathrm{MPa}$ and $20^{\circ} \mathrm{C}$ for 2 min to remove the most of bulk water. Compressed $\mathrm{BC}$ pellicles were heated in $500 \mathrm{ml}$ of acetic anhydride at $120^{\circ} \mathrm{C}$ for $21 \mathrm{~h}$. Acetylated $\mathrm{BC}$ pellicles were washed under running tap water for 2 days and then pressed at $2 \mathrm{MPa}$ and $120{ }^{\circ} \mathrm{C}$ for 4 min to completely remove water. The acetylated BC sheets thus obtained were $30 \times 40 \mathrm{~mm}^{2}$ and $45 \pm 5 \mu \mathrm{m}$ thick with a density of $1.2-1.3 \mathrm{~g} / \mathrm{cm}^{3}$.

Based on scanning electron microscopy (SEM) images, the width of the nanofibers was found not to change after acetylation and the network structure was preserved (Fig. 1). Furthermore, X-ray analyses indicated that the crystallinity of $\mathrm{BC}$ did not change due to the acetylation, although the degree of substitution of acetylated BC sheets determined by elemental analysis was 0.17 .

From the SEM images, it was also observed that the acetylated $\mathrm{BC}$ nanofibers are separated from each other in the sheet [Fig. 1(b)]. In contrast to this, the untreated BC nanofibers are so densely packed that the interstitial cavities are imperceptible [Fig. 1(a)]. The replacement of the surface hydroxyl groups by acetyl groups may interfere with mutual bonding of $\mathrm{BC}$ nanofibers to each other during the hot pressing to obtain dry sheets.

The $\mathrm{BC}$ sheets were impregnated with neat acrylic resins [type tricyclodecane dimethanol dimethacrylate (TCDDMA) with a refractive index of 1.532 and ABPE300 with a refractive index of 1.570, Mitsubishi Chemical Corp.) under reduced pressure and cured by UV light.

The BC nanocomposite with $60 \mathrm{wt} \%$ nanofibers reached a moisture content (MC) of $3.12 \%$ at $20{ }^{\circ} \mathrm{C}$ and $55 \%$ relative humidity whereas the neat acrylic resin TCDDMA reached a 

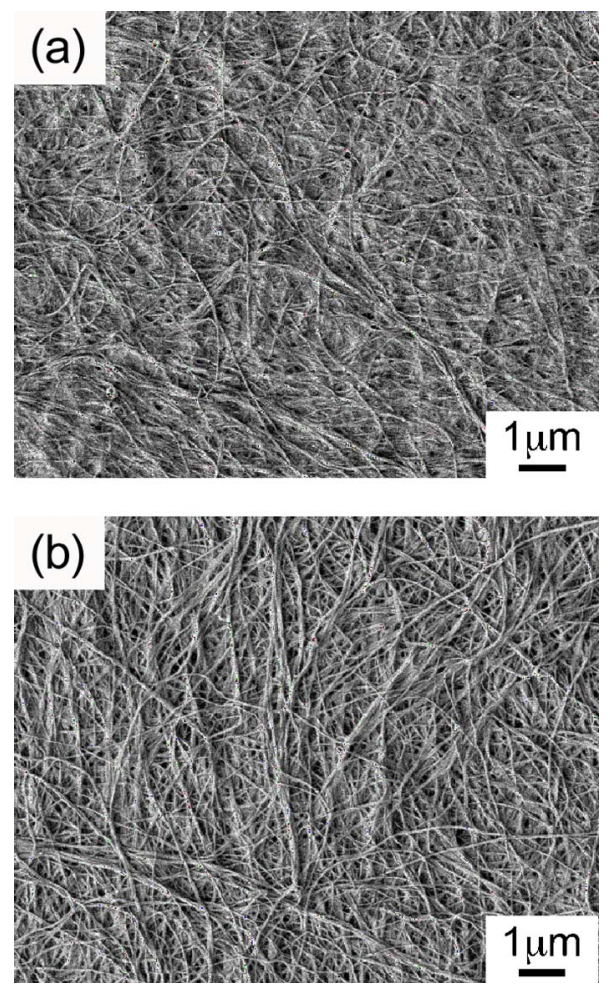

FIG. 1. SEM images of (a) untreated BC sheet and (b) acetylated BC one.

MC of only $0.35 \%$ under the same conditions. When the fiber content of $\mathrm{BC}$ nanocomposites decreased from 60 to $35 \mathrm{wt} \%$, their moisture content decreased from $3.12 \%$ to $1.49 \%$. Interestingly, the acetylated $\mathrm{BC}$ nanocomposites adsorbed only $1.33 \% \mathrm{MC}$ although the fiber content was as high as $66 \mathrm{wt} \%$. This shows that $0.17^{\circ}$ of substitution by acetyl groups produces a significant reduction in the hygroscopicity of BC nanofibers. As a consequence, when the fiber content was reduced to $33 \mathrm{wt} \%$ in combination with acetylation, a moisture content of only $0.80 \%$ was obtained. This is similar to that of the neat acrylic resin of TCDDMA.

The regular light transmittances of the acetylated $\mathrm{BC}$ nanocomposites were evaluated using a UV-visible spectrometer (U-4100, Hitachi High-Tech. Corp.). The acetylated BC nanocomposites exhibited high optical transparency, as shown in Fig. 2. Furthermore, when the spectra are compared carefully, the transparency of BC nanocomposites impregnated with TCDDMA (refractive index: 1.532) improved due to the acetylation [Fig. 2(a)]. For example, at the wavelength of $400 \mathrm{~nm}$, the regular transmittance of untreated BC nanocomposite was $72.4 \%$, while that of acetylated $\mathrm{BC}$ nanocomposite was $76.6 \%$. In contrast, when an acrylic resin ABPE300 having a refractive index of 1.570 was impregnated, the regular transmittance of $\mathrm{BC}$ nanocomposite deteriorated with acetylation, especially at shorter wavelengths [Fig. 2(b)]. In a previous study, we reported that the highest transparency of $\mathrm{BC}$ nanocomposites was attained at the refractive index of 1.570 (ABPE300), corresponding to the average refractive index of cellulose fiber. ${ }^{5}$ Considering that the refractive index of cellulose acetate decreases with the increase of the degree of substitution, ${ }^{13}$ the refractive index of $\mathrm{BC}$ would change due to acetylation. As a consequence, the optimum matrix refractive index for high transparency may shift. different heating times. When the samples were subjected to
Downloaded 24 Aug 2009 to 130.54.110.32. Redistribution subject to AlP license or copyright; see http://apl.aip.org/apl/copyright.jsp
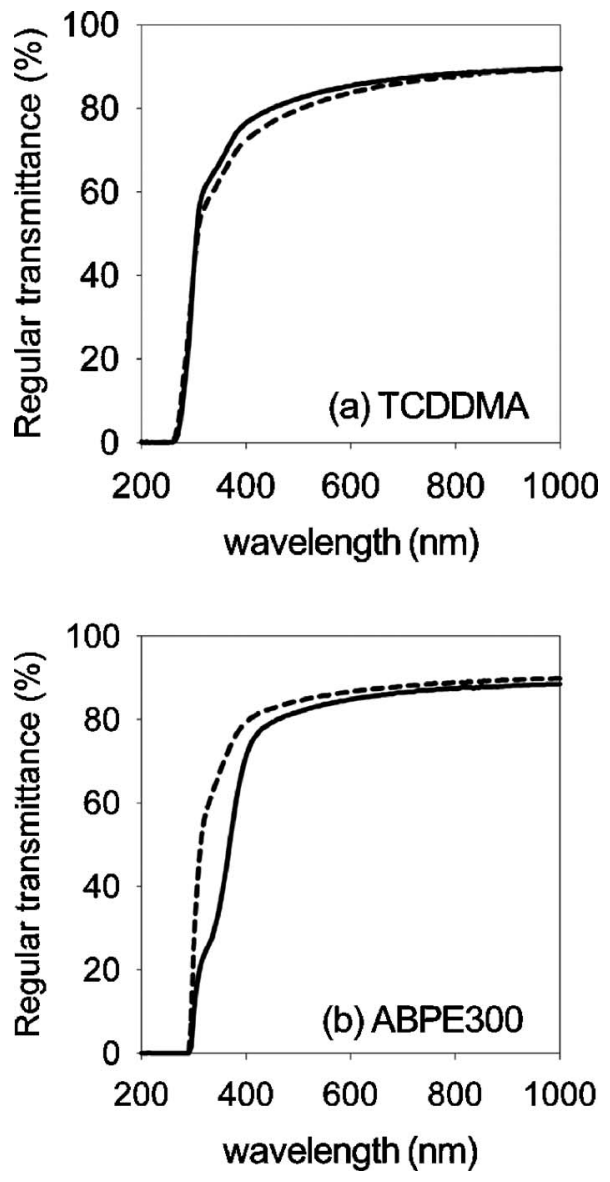

FIG. 2. Regular transmittance spectra of acetylated (solid line) and untreated (broken line) BC nanocomposites. (a) Acetylated BC nanocomposite (65 $\mu \mathrm{m}$ thick, $53 \mathrm{wt} \%)$ and untreated one (63 $\mu \mathrm{m}$ thick, $56 \mathrm{wt} \%)$ with the matrix resin of TCDDMA acrylic resin with a refractive index of 1.532 and (b) acetylated BC nanocomposite (68 $\mu \mathrm{m}$ thick, $63 \mathrm{wt} \%)$ and untreated one (73 $\mu \mathrm{m}$ thick, $59 \mathrm{wt} \%$ ) with the matrix resin of ABPE300 acrylic resin with a refractive index of 1.570 .

The CTEs at $20-150{ }^{\circ} \mathrm{C}$ were evaluated using a thermomechanical analyzer (TMA/SS6100, SII Nanotechnology, Inc.). Interestingly the acetylation resulted in extremely low CTE of BC sheet $(0.8 \mathrm{ppm} / \mathrm{K})$, as compared to the CTE of untreated $\mathrm{BC}$ sheet $(3 \mathrm{ppm} / \mathrm{K})$. These results suggest that the acetylated $\mathrm{BC}$ nanofibers would enable further reduction of $\mathrm{CTE}$ in the nanocomposites. The addition of $66 \mathrm{wt} \%$ of acetylated $\mathrm{BC}$ nanofibers reduced the CTE of acrylic resin from 86 to $8 \mathrm{ppm} / \mathrm{K}$. However, the untreated $\mathrm{BC}$ nanocomposite at a fiber content of $60 \mathrm{wt} \%$ also exhibited a similar CTE of $8 \mathrm{ppm} / \mathrm{K}$. We found that Young's modulus of BC sheets was reduced from 23.1 to $17.3 \mathrm{GPa}$ due to the acetylation. This is probably because the acetylated $\mathrm{BC}$ nanofibers have fewer fiber-fiber interactions due to a decreased number of hydrogen bonds. Although sheets based on acetylated BC nanofibers have very low CTE, the reduced number of fiberfiber interactions reduces the capability of the nanofiber network to restrain thermal expansion of a polymer matrix. This implies that if the number of fiber-fiber interactions is increased in acetylated $\mathrm{BC}$ sheets, the CTE of the resulting nanocomposites would be reduced.

Acetylation has been reported to improve the thermal degradation resistance of cellulosic fibers, such as jute ${ }^{14}$ and sisal. ${ }^{15,16}$ The effects of acetylation on the thermal degradation of optical transparency were evaluated at $200{ }^{\circ} \mathrm{C}$ for 

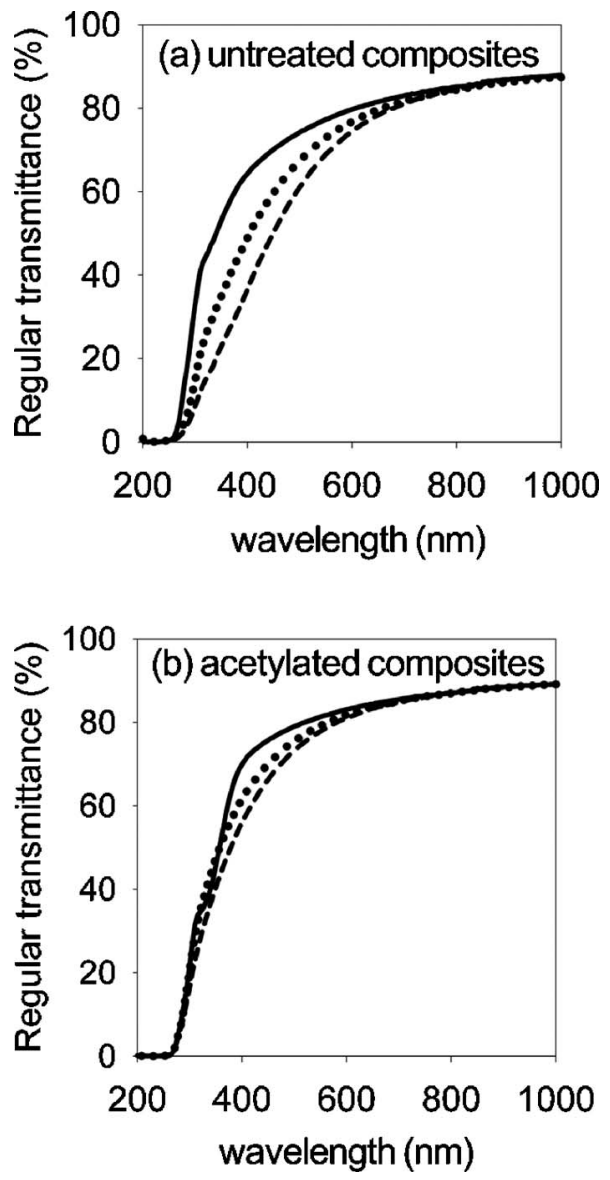

FIG. 3. Regular transmittance spectra of BC nanocomposites with the matrix of TCDDAMA before (solid line) and after heating at $200^{\circ} \mathrm{C}$ for $1 \mathrm{~h}$ (dotted line) and $3 \mathrm{~h}$ (broken line). (a) Untreated $\mathrm{BC}$ nanocomposite $(73 \mu \mathrm{m}$ thick, $64 \mathrm{wt} \%)$ and (b) acetylated BC nanocomposite $(80 \mu \mathrm{m}$ thick, 61 wt \%).

$200{ }^{\circ} \mathrm{C}$ in air for $3 \mathrm{~h}$, the optical transparency of untreated and acetylated $\mathrm{BC}$ nanocomposites was reduced as reported in Fig. 3. The acrylic resin sheet maintained its transparency. However, the reduction in transparency of acetylated BC nanocomposites was much smaller than for the untreated $\mathrm{BC}$ nanocomposites (Fig. 3). At the wavelength of $400 \mathrm{~nm}$, the regular transmittance of untreated $\mathrm{BC}$ nanocomposite was decreased to $48.9 \%$ after heating for $1 \mathrm{~h}$ at $200{ }^{\circ} \mathrm{C}$ [Fig. $3(\mathrm{a})]$. On the other hand, the regular transmittance of acetylated $\mathrm{BC}$ nanocomposite was $56.0 \%$ even after heating for
$3 \mathrm{~h}$ at $200{ }^{\circ} \mathrm{C}$ [Fig. 3(b)]. Acetylation proved to be effective for improving the thermal degradation resistance of $\mathrm{BC}$ nanocomposites, which is a prerequisite to a wider use of $\mathrm{BC}$ nanocomposites in optoelectronic devices.

In conclusion, we fabricated nanocomposites reinforced with acetylated BC nanofibers. The acetylated BC nanocomposites showed reduced moisture adsorption and improved thermal degradation resistance regarding transparency. Furthermore, because the acetylated $\mathrm{BC}$ nanofibers attained extremely low CTEs, the acetylated $\mathrm{BC}$ nanofibers have the potential to enable a further reduction of CTE in the nanocomposites. Thus, the acetylation of bionanofibers is a promising modification for property enhancement of optically transparent materials, which require high transparency and low thermal expansion.

BC pellicles were a kind gift from Y. Kuwana (Fujicco Co., Ltd.). The authors would like to thank A. N. Nakagaito, RISH, Kyoto University for helpful discussion. They would also like to thank L. Berglund, Biofibre Materials Centre, Royal Institute of Technology for valuable revision of this letter. This work was supported by a grant-in-aid from the International Innovation Center, Kyoto University.

${ }^{1}$ P. Ross, R. Mayer, and M. Benziman, Microbiol. Rev. 55, 35 (1991).

${ }^{2}$ R. M. Brown, J. Macromol. Sci., Pure Appl. Chem. A33, 1345 (1996).

${ }^{3}$ M. Iguchi, S. Yamanaka, and A. Budhiono, J. Mater. Sci. 35, 261 (2000).

${ }^{4}$ H. Yano, J. Sugiyama, A. N. Nakagaito, M. Nogi, T. Matsuura, M. Hikita, and K. Handa, Adv. Mater. (Weinheim, Ger.) 17, 153 (2005).

${ }^{5}$ M. Nogi, K. Handa, A. N. Nakagaito, and H. Yano, Appl. Phys. Lett. 87, 243110 (2005).

${ }^{6}$ D. H. Page and F. EL-Hosseiny, J. Pulp Pap. Sci. 9, 99 (1983).

${ }^{7}$ T. Nishino, T. Takano, and K. Nakamae, J. Polym. Sci., Part B: Polym. Phys. 33, 1647 (1995).

${ }^{8}$ Introduction to Physical Polymer Science, edited by L. H. Sperling (Wiley, New York, 2001), Chap. 11, p. 499.

${ }^{9}$ T. Nishino, I. Matsuda, and K. Hirao, Macromolecules 37, 7683 (2004).

${ }^{10}$ M. Nogi, S. Ifuku, K. Abe, K. Handa, A. N. Nakagaito, and H. Yano, Appl. Phys. Lett. 88, 133124 (2006).

${ }^{11}$ The Chemistry of Solid Wood, edited by R. M. Rowell (American Chemical Society, Washington, DC, 1984), Chap. 4, p. 183.

${ }^{12}$ A. K. Bledzki and J. Gassan, Prog. Polym. Sci. 24, 221 (1999).

${ }^{13}$ H. Boerstoel, H. Maatman, S. J. Picken, R. Remmers, and J. B. Westerink, Polymer 42, 7363 (2001).

${ }^{14}$ A. K. Rana, R. K. Basak, B. C. Mitra, M. Lawther, and A. N. Banerjee, J. Appl. Polym. Sci. 64, 1517 (1997).

${ }^{15}$ C. Albano, J. Gonzalez, M. Ichazo, and D. Kaiser, Polym. Degrad. Stab. 66, 179 (1999).

${ }^{16}$ M. N. Ichazo, C. Albano, and J. Gonzalez, Polym. Int. 49, 1409 (2000). 